\title{
LA SUSPENSION DE LA EXPROPIACION: EL “FUMUS BONIS IURIS" COMO CRITERIO DETERMINANTE PARA LA ADOPCION DE UNA MEDIDA CAUTELAR (Auto del Tribunal Superior de Justicia de Navarra de 19 de Noviembre de 1990).
}

POR

Jose SUAY RINCON

SUMARIO: I. INTRODUCCION. II. SUSPENSION Y EXPROPIACION: PLANTEAMIENTO DE LA CUESTION; A) Los hechos; B) Expropiación: garantías constitucionales. III. SUSPENSION Y MEdidAS CAUTELARES: el Auto del TribUNAL Superior de Justicia de Navarra de 19 de Noviembre de 1990; A) Auto inicial denegatorio de la suspensión: alternativas; B) Las razones de un cambio: la aplicación del "fumus bonis iuris".

\section{I.- INTRODUCCION}

El artículo 1 de la Ley de 16 de Diciembre de 1954 define la expropiación forzosa en los más amplios términos: "cualquier forma de privación singular de la propiedad privada o de derechos o de intereses patrimoniales legítimos, cualesquiera que fueren las personas o Entidades a que pertenezcan, acordada imperativamente, ya implique venta, permuta, censo, arrendamiento, ocupación temporal o mera cesación de su ejercicio".

Como es evidente, no vamos a descubrir ahora la expropiación forzosa. Es ésta una técnica clásica de intervención, sobradamente conocida, y resultado de un procedimiento cuyo protagonismo corresponde, en nuestro Derecho positivo, a la Administración Pública.

Sentado esto, se hace preciso, sin embargo, efectuar una puntualización de capital importancia: a pesar de su indiscutible arraigo, es esta una institución cuyo tratamiento actual dista mucho de ser satisfactorio.

La Ley de 1954 antes mencionada ha seguido vigente hasta nuestros días sin apenas cambios, como si nada hubiese ocurrido desde entonces. Su esqueleto básico se ha mantenido intacto y cuando, además, ha experimentado algún tipo de modificación (vía legislación 
estatal sectorial o vía legislación autonómica), la tendencia ha ido casi siempre encaminada a imprimir una mayor velicidad al procedimiento expropiatorio, lo que lleva consigo una considerable reducción de las garantias de los propietarios afectados. El objeto habitual ha sido, en última instancia, adelantar el momento de la ocupación del bien expropiado, a fin de que, consumada así la expropiación, quedara eliminada de entrada todo tipo de controversia en torno a ella.

Da la impresión de que la aparición de un texto jurídicamente tan relevante como la Constitución española de 1978 apenas se ha hecho sentir en esta materia. $Y$ eso que el artículo 33 incluye la propiedad privada en el catálogo de los Derechos Fundamentales reconocidos en el Título I, y que el apartado tercero de este mismo precepto expresamente dispone que "nadie podrá ser privado de sus bienes y derechos sino por causa justificada de utilidad pública o interés social, mediante la correspondiente indemnización y de conformidad con los dispuesto por las leyes".

Relacionando este precepto con el artículo 24, que reconoce el derecho fundamental a una tutela judicial efectiva, es posible deducir alguna conclusión de alcance general sobre la configuración del procedimiento expropiatorio $y$, en particular, sobre las garantías de los propietarios expropiados en el curso del mismo.

El Auto dictado por el Tribunal Superior de Justicia con fecha 19 de Noviembre de 1990 permite reflexionar sobre todo ello, y de ahi su interés, interés que se acrecienta por el hecho de que el citado Auto es expresión de una línea jurisprudencial en materia de medidas cautelares de la que igualmente interesa dejar constancia.

\section{II.- SUSPENSION Y EXPROPIACION: PLANTEAMIENTO DE LA CUESTION.}

\section{A) Los hechos.}

En síntesis, el relato de los hechos que conduce hasta la adopción del Auto objeto de este comentario es el que sigue:

Con fecha 8 de Junio de 1989 el Parlamento de Navarra aprueba la Ley Foral de medidas de intervención en materia del suelo y vivienda (Ley 7/1989), cuyo artículo 29. 1 dice asi: "La expropiación urbanistica podrá tener cualquiera de las siguientes finalidades: b) Constitución de reservas de suelo para la promoción de viviendas o de usos industriales o terciarios en aquellas zonas delimitadas por Decreto Foral para el ejercicio del derecho de tanteo o 
retracto por el Gobierno de Navarra o en aquellas zonas previstas en el planeamiento comarcal o local".

Esta disposición va a llevarse rápidamente a efecto: el 3 de Agosto de 1989 el Gobierno de Navarra aprueba inicialmente una delimitación de zonas sometidas al ejercicio del derecho de tanteo y de retracto, $y$ el expediente instruido a continuación es aprobado definitivamente por Decreto Foral 30/1990, de 15 de Febrero, que en su artículo 2 prevé ya la expropiación urbanística de una serie de terrenos. Entre los terrenos a expropiar -y hay que resaltar que esta previsión (la expropiación) no figuraba en el acuerdo de aprobación inicial- figuran los del propietario que a continuación entablará el litigio que conducirá hasta el Auto objeto de este comentario.

A partir de aquí, los acontecimientos van a precipitarse. Poco después, la Comunidad Foral aprueba por Orden 258/1990, de 3 de Marzo, la modificación del planeamiento urbanistico vigente en la zona, a fin de acomodarlo a la nueva situación surgida del Decreto Foral 30/1990 antes mencionado, cambiando concretamente el sistema de ejecución de una de las unidades previsto por el Plan provisionalmente aprobado (cooperación o compensación) por el de expropiación.

Más tarde, el 18 de Mayo de 1990 se produce el Acuerdo del Gobierno de Navarra declarando de utilidad pública la expropiación. La Orden Foral 317/1990, de 25 de Mayo, aprueba inicialmente y somete a información pública la delimitación del ámbito territorial sobre el que va a recaer la expropiación, incluyendo una relación concreta de los bienes afectados, y la Orden Foral 437/1990, de 28 de Junio, aprobará definitivamente dicha delimitación desestimando las alegaciones presentadas. Por último, la Orden Foral 451/1990, de 2 de Julio, dispone la aprobación inicial del expediente de tasación conjunta, y el Acuerdo de 26 de Octubre de 1990 decretará la aprobación definitiva de dicho expediente, declarando de urgencia la ocupación inmediata de la finca.

En tan angustiosas circunstancias, a punto de producirse la ocupación (la expropiación es luego irreversible), llega el Auto del Tribunal Superior de Justicia de Navarra de 19 de Noviembre de 1990 declarando en suspenso la expropiación. Lo que se suspende, concretamente, es el Acuerdo de declaración de utilidad pública que el Gobierno de Navarra habría aprobado con fecha 18 de Mayo de 1990.

\section{B) Expropiación: garantías constitucionales.}

En contraste con otras instituciones -seria, por ejemplo, el caso de las sanciones administrativas-, la expropiación forzosa no ha sido 
objeto de los debidos reajustes, con el fin de acomodarla a los nuevos principios constitucionales. Realmente, resulta una de las parcelas del Derecho Administrativo que, hoy por hoy, se encuentra en peor estado.

En principio, la explicación es sencilla: la expropiación forzosa es una técnica que se desarrolla en tiempos de expansión o de bonanza económica. Sin dinero, claro está, no puede haber expropiaciones.

Ya desde antes de aprobada la Constitución, y durante casi un decenio, han corrido tiempos de crisis. $Y$ con la situación en franca regresión, la expropiación se retiró al "cuarto de los trastos". Apenas se vislumbraron, sin embargo, los primeros atisbos de salida a dicha crisis, los poderes públicos desempolvaron la figura y el legislador, concretamente, revitalizó su juego, multiplicando, a resultas de ello, los supuestos expropiatorios.

Por supuesto, nada hay que objetar a este proceso, que, es de suponer, se realiza en beneficio del interés general y, por tanto, de la comunidad en su conjunto. Ocurre, sin embargo, que el desarrollo de la institución se ha hecho sin acompañar a la misma las debidas garantías (ya se destacó al inicio de este trabajo: mayor celeridad del procedimiento expropiatorio, adelantamiento del momento de la ocupación, etc.).

En este contexto se comprende ya la importancia del Auto de suspensión, objeto de este comentario. Dicho Auto tiene interés, porque detiene la expropiación al principio, en el único momento donde la suspensión tiene efectividad: con motivo de la declaración de utilidad pública de la expropiación.

Una reflexión general sobre la institución que nos ocupa se impone, y dicha reflexión debe comenzar por la toma de conciencia de un hecho que, en nuestra opinión, resulta indiscutible: la expropiación forzosa es el resultado de un largo procedimiento administrativo, en el que lo verdaderamente decisivo se ventila, sin embargo, en los momentos iniciales. A esa fase, por tanto, hay que adelantar el debate jurídico en torno a ella -¿es verdaderamente indispensable la expropiación? ¿existen otras alternativas viables y menos gravosas?, estableciéndose, concretamente:

- Un trámite contradictorio, al menos, dentro del propio procedimiento expropiatorio, que permita contestar tanto la utilidad pública de la expropiación (efectiva concurrencia de la causa expropiandi) como el acuerdo de necesidad de ocupación (existencia de otras alternativas más apropiadas).

- $Y$, asimismo, el acceso inmediato, sin tener que esperar al final del procedimiento, a los Tribunales de Justicia, Tribunales que, podrán, además, adoptar en su caso las 
medidas cautelares precisas para garantizar la integridad de la litis y la efectividad de sus resoluciones (sobre el control judicial de la declaración de utilidad pública vid. FERNANDEZ RODRIGUEZ, T.R., EI control jurisdiccional de la causa expropiandi, "REDA", 1 (1974), pág. 119 y sigs.; sobre el control judicial de la necesidad de ocupación vid. DE JUAN ORLANDIS, D., Hacia el control jurisdiccional, en cuanto al fondo, del acuerdo de necesidad de ocupación en el procedimiento expropiatorio, "La Ley", 22 de Abril de 1986).

La novedad de este planteamiento -que, en realidad, se asemeja mucho al que impulsó la redacción de la Ley de Expropiación Forzosa de 1954: vid. GARCIA DE ENTERRIA, Los principios de la nueva Ley de Expropiación Forzosa, Madrid, Civitas, $2^{\mathrm{a}}$ ed., 1984- estaría en que el mismo no sólo es perfectamente posible $y$ hasta deseable (más tarde, cuando la expropiación ya está en marcha, todo queda prácticamente limitado a discutir sobre la corrección del justiprecio fijado de forma unilateral por la Administración; de manera notoria, en las expropiaciones urgentes, las más frecuentes, en las que, como es sabido, la ocupación precede al pago del justiprecio), sino exigible en términos estrictos, a partir de los artículos 33 y 24 de la Constitución:

-Empezando por el artículo 33, ha de recordarse que, junto al requisito de la indemnización o justiprecio, este precepto menciona otro que igualmente debe cumplirse en toda expropiación: la concurrencia de una causa de utilidad pública o de interés social. Resulta, pues, que no es válida constitucionalmente cualquier operación expropiatoria, ni siquiera sería válida una expropiación acompañada de un generoso justiprecio; aquélla ha de obedecer igualmente a una causa de utilidad pública o de interés social. Así lo exige el artículo 33; si no, se produciría irremediablemente una vulneración del derecho fundamental a la propiedad privada, que, en términos positivos podemos decirlo así-, exige la concurrencia de la "causa expropiandi"

Esta es una apreciación que la Administración realiza al principio del procedimiento expropiatorio, y de ahí que en el interior del mismo deba preverse un trámite contradictorio, de las características que antes hemos apuntado, que permita la discusión sobre todas las alternativas posibles. Una Ley que, por hipótesis, ignorara esta exigencia sería irremediablemente inconstitucional por infracción del artículo 33 
de la Constitución (a no ser, lógicamente, que se oponga a este valor constitucional otro del mismo rango).

- Pero todavía hay más. Si recordamos ahora el artículo 24, que reconoce el derecho a una tutela judicial efectiva, la conclusión resulta obligada: no basta asegurar la contracción en el ámbito del procedimiento administrativo; para que la Justicia sea realmente efectiva y no llegue demasiado tarde, es forzoso también arbitrar las vías procesales adecuadas para que Jueces y Tribunales puedan intervenir en el asunto desde el principio derecho al recurso contencioso-administrativo ex constitutione, y no meramente ex lege- y para que en su caso aquéllos dicten las medidas apropiadas para garantizar la integridad del objeto litigioso y la efectividad de sus resoluciones -la suspensión de la expropiación-.

En nuestra opinión, estas son dos conclusiones que (como mínimol se deducen para la expropiación de los artículos 33 y 24 de la Constitución.

\section{III.- SUSPENSION Y MEDIDAS CAUTELARES:EL AUTO DEL TRIBUNAL SUPERIOR DE JUSTICIA DE NAVARRA DE 19 DE NOVIEMBRE DE 1990.}

El Auto objeto de este comentario, sin embargo, no sólo tiene interés para la teoría de la expropiación, sino también para la de las medidas cautelares, y ello en un doble plano, tanto en lo que respecta a su régimen jurídico-procesal, como en lo que hace a su régimen jurídico-material.

\section{A) Auto inicial denegatorio de la suspensión: alternativas.}

El Auto de 19 de Noviembre de 1990 ha seguido una curiosa tramitación procesal: es, en realidad, revocación de otro anterior del mismo Tribunal que había resuelto negativamente el incidente de la suspensión.

Interesa conocer de forma pormenorizada cómo se ha desarrollado la tramitación del incidente, porque de ella siguen algunas consecuencias de interés para el régimen procesal de las medidas cautelares:

El recurrente solicitó la suspensión en el primer momento en que pudo hacerlo: al interponer, pues, el recurso contenciosoadministrativo, tal como es del todo habitual. 
La suspensión, sin embargo, fue denegada inicialmente por la Sala mediante Auto de 5 de Julio de 1990. Los perjuicios que la expropiación supone para el recurrente son evidentes y han sido tenidos presentes por la Sala desde el principio. Ocurre, sin embargo, que ésta daba prevalencia al interés general concurrente en el caso:

“Si bien en principio se apreciaban daños y perjuicios claros y evidentes para el particular afectado - . . . . . . . . . . . . . . . (......................................) - -, sin embargo considerábamos que tal suspensión podría afectar gravemente al interés general".

Contra esta resolución, el particular promovió, primero, recursos de apelación (recurso que se rige por las mismas reglas que la apelación contra sentencias y que, por tanto, ha de seguir todos y cada uno de los trámites procesales establecidos en el mismo -interposición, comparecencia y alegaciones-, lo que alarga extraordinariamente el procedimiento y de facto hace inservible la suspensión como medida cautelar).

Más tarde, sin embargo, el recurrente aprovechó el trámite de la formalización de la demanda para volver a plantear la cuestión ante la Sala. Se pusieron entonces de manifiesto una serie de hechos que hasta ese momento eran desconocidos por ésta:

"En la demanda, la parte actora volvió a solicitar nuevamente la suspensión, por otrosí, volcando en esta petición todos los argumentos, respaldados por documentos, que le sirven para pedir la estimación del recurso y la declaración de nulidad del acuerdo impugnado".

Ha de recordarse que la interposición del recurso (cuando se solicitó la suspensión por primera vez) tiene lugar por medio de un escrito cuyo único objeto es identificar el acto impugnado al objeto de reclamar a la Administración el expediente correspondiente. De ahí la reiteración de la solicitud de suspensión al formalizar la demanda y dar a conocer de forma pormenorizada las razones del conflicto.

Estando, sin embargo, el recurso de apelación pendiente de resolución, el Tribunal "a quo" estimó acertadamente que no podía proveer a lo solicitado:

“Esta solicitud no pudo ser admitida a trámite por cuanto estando pendiente de apelación, nosotros habíamos perdido jurisdicción". 
El particular tuvo, pues, que desistir de dicho recurso y volver a solicitar la suspensión:

"Mas, renunciada la apelación, se vuelve a instar ahora la suspensión apoyándose esencialmente en los argumentos expuestos en la demanda y aportando fotocopias de diarios de la localidad en el que se toca la temática de las viviendas de protección oficial, recogiendo datos oficiales sobre la inmediata construcción de varios miles de ellas".

Esta vez (la tercera) fue la buena y la suspensión fue, al fin, otorgada por Auto de 19 de Noviembre de 1990.

A la vista de estos hechos, y limitándose por ahora a un plazo estrictamente procesal, cabe deducir lo siguiente:

Obtenida inicialmente una respuesta negativa a la suspensión solicitada, las posibilidades que se le ofrecen al recurrente son dos: - Interponer recurso de apelación ante el Tribunal Superior; - Volver a plantear la cuestión ante la propia Sala.

Ambas alternativas son posibles: la primera, sin embargo, lleva tanto tiempo que de facto resulta inservible; la segunda es mucho más rápida y expeditiva $y$, en consecuencia, preferible. No obstante, si de elegir se trata, hay que tener presente que sólo cabe volver a plantear la cuestión ante la Sala si se aducen realmente hechos nuevos o si se apuntan razones $y$ argumentos no esgrimidos con anterioridad. Es posible interpretar con una cierta flexibilidad la concurrencia de esta circunstancia, pero la elección no es del todo discrecional.

En cualquier caso, lo que debe resaltarse es que, pese a ser posibles, ambas vías no son compatibles y la utilización de una precluye la de la otra. De forma que interpuesto recurso de apelación, el particular debe desistir del mismo si quiere volver a plantear la cuestión ante la Sala.

\section{B) Las razones de un cambio: la aplicación del "fumus - bonis iuris".}

El Auto del Tribunal Superior de Justicia de Navarra de 19 de Noviembre de 1990 suspende la ejecución del Acuerdo de declaración de utilidad pública de la expropiación adoptado por el Gobierno de Navarra. Lo hace por un conjunto de razones que básicamente se recogen en el Fundamento Jurídico Cuarto, que ahora se transcribe íntegro: 
"Los argumentos expuestos en la demanda y que ahora se invocan para pedir la suspensión así como la importante prueba documental aportada, nos han convencido ahora de lo contrario, es decir de que debemos proceder a la suspensión de la ejecutividad del acuerdo impugnado, ello por las siguientes razones:

a) el interés general inmediato basado en la exigencia de construcción de "viviendas protegidas" está cubierto suficientemente con la actuación del Gobierno de Navarra y de otros municipios, de forma y manera que el acuerdo ahora objeto de solfa, en cuanto sea suspendido no va a influir mínimamente en todo el programa de construcción y en sus resultados, de forma y manera que antes de expropiar definitivamente vamos a ver las necesidades de tal medida, y su ajuste a la legalidad, no sea que luego, una vez llevado a cabo el acuerdo, la resolución que se dicte sea favorable al actor y el retorno a la situación anterior sea imposible; quede pues en suspenso el acuerdo por cuanto no incide la suspensión en el interés general si el Gobierno de Navarra hace lo que dijo que haría, y no se carguen solo las tintas sobre esta parte actora; b) pero es que, además, se nos está demostrado indiciariamente que la parte actora lleva trabajando activamente y sin descanso de cara a una auténtica y eficaz actividad constructora, y que, en realidad, nos parece que no está encontrando más que trabas, en los últimos tiempos, en ningún caso a ella imputables, con graves pérdidas y quebrantos económicos; c) también vemos, indiciariamente -porque tenemos que recorrer un largo trecho hasta la sentencia y es allá donde deberemos pronunciarnos, sin que ahora podamos eludir, por otro lado, ciertas apreciaciones y matizaciones- que tal vez sea más acertado para el interés general el proyecto de la parte actora que el del Gobierno de Navarra en este concreto caso, y piénsese que la propia Corporación Local directamente afectado e interesado, ya ha reaccionado en tal sentido; por algo será; d) pero es que, por colmo, nos encontramos con que la normativa en que se apoyan las resoluciones combatidas también se encuentra en solfa y a estos solos efectos citaremos el artículo 78. 3 de la nueva Ley del Suelo 8 (1990, de 8 de Julio, y aunque la incidencia de esta Ley tanto en el caso concreto, como en la normativa navarra en general, deba determinarse en la sentencia, sin embargo la mínima prudencia judicial aconseja suspender el acuerdo impugnado, por esto y por lo anteriormente apuntado". 
Así, pues, en concreto cuatro razones: "- El interés general inmediato basado en la exigencia de construcción de "viviendas protegidas" está cubierto suficientemente con la actuación del Gobierno de Navarra y de otros municipios, de forma y manera que el acuerdo ahora objeto de solfa, en cuanto sea suspendido no va a influir mínimamente en todo el programa de construcción y en sus resultados; - la parte actora lleva trabajando activamente $y$ sin descanso de cara a una auténtica y eficaz actividad constructora, y que, en realidad, nos parece que no está encontrando más que trabas, en los últimos tiempos, en ningún caso a ella imputables, con graves pérdidas y quebrantos económicos; - tal vez sea más acertado para el interés general el proyecto de la parte actora que el del Gobierno de Navarra en este concreto caso, y piénsese que la propia Corporación Local, directamente afectada e interesada ya ha reaccionado en tal sentido; - la normativa en que se apoyan las resoluciones combatidas también se encuentra en solfa y a estos solos efectos citaremos el artículo 78. 3 de la nueva Ley del Suelo 8/1990 de 8 de Julio".

La conclusión alcanzada parece la más natural. Los intereses de todos parecen converger en el mismo punto (el interés general, el de la Corporación Local afectada, el del propietario expropiado). No obstante, hay algo que escapa de lo habitual, y es por lo que el Auto presenta particular interés. En la primera ocasión, la Sala había denegado la suspensión solicitada. La "necesidad imperiosa de viviendas sociales" había sido el argumento determinante:

\begin{abstract}
"es conocida la necesidad imperiosa de "viviendas sociales" así como la gran demanda existente hoy día, no desconociendose el movimiento especulativo enormemente alcista permitido en estos últimos años e incluso, a veces, provocado por la propia Administración -piénsese por ejemplo en la venta de terrenos municipales del Ayuntamiento de Pamplona llevada a cabo en años anteriores-. Todo este movimiento especulativo ha producido un endiablado encarecimiento de la vivienda la que, además de cara es pequeña y mala: también esto es público, notorio y conocido. En nuestro anterior Auto nos inclinamos por la no suspensión del acuerdo impugnado, en aras a la defensa del interés general, en base a estas y otras consideraciones socio-económicas".
\end{abstract}

¿Qué factores impulsan ahora al cambio de criterio? En este punto está lo verdaderamente interesante. Los perjuicios del propietario expropiado han sido indiscutibles desde el principio. Lo que se produce, pues es una reinterpretación del interés general, y ello a 
partir de una reflexión más detenida y profunda del problema:

"Lo que sí vamos a hacer, es examinar nuevamente el caso concreto, una vez que la recurrente nos aporta más datos y elementos de juicio, entre los que destaca una interesante prueba documental".

Una reflexión apoyada ahora en una serie de datos y de argumentos desconocidos hasta la fecha: son los que resultan de la demanda y de los documentos que se acompañan a ésta. El Auto mismo reconoce esta circunstancia y la subraya con especial énfasis:

"Los argumentos expuestos en la demanda y que ahora se invocan para pedir la suspensión asi como la importante prueba documental aportada, nos ha convencido ahora de lo contrario, es decir, de que debemos proceder a la suspensión de la ejecutividad del acuerdo impugnado".

Asi, pues, sobre esto no cabe hacerse la menor cuestión. La suspensión se había solicitado en el primer instante, en el momento de la interposición del recurso, antes de presentada la demanda y desconocida, por tanto, la fundamentación real de las pretensiones de las partes. Entonces, la suspensión es denegada. Después de la demanda, el panorama da un vuelco de ciento ochenta grados. Pese a haber resuelto ya en una ocasión, y pese a la existencia de un recurso de apelación, una vez que de éste se desiste, la Sala no encuentra problema de admisibilidad, entra en el fondo y acuerda la suspensión. ¿Por qué? El Tribunal tiene ya acceso a las posiciones de las partes, está en condiciones de profundizar en la cuestión y de formarse un juicio. Un juicio preliminar y provisional, desde luego, pero un juicio ya sobre el conflicto que debe arbitrar.

De ese juicio meramente preliminar, de esa impresión inicial que extrae del asunto ( $y$ sin prejuzgar, como es natural, el fondo del mismo), resulta la verdadera razón del cambio de opinión. La conclusión es indiscutible: el Tribunal aplica el "fumus bonis iuris" como criterio para el otorgamiento de la suspensión.

Hasta la demanda, el Tribunal desconocía realmente la solidez de las tesis defendidas por las partes. En tales condiciones, no hay fumus posible, en principio. Con posterioridad, todo cambia. Con el expediente y la demanda se conocen los argumentos sobre los que descansan las pretensiones de unos y otros, el Tribunal puede ya formarse un juicio provisional y en función del resultado de dicho juicio, resuelve el in- 
cidente: en nuestro caso, sirve, ademas, para rectificar la decisión anterior, dando lo que antes había sido denegado.

El Fundamento Cuarto del Auto antes transcrito está plagado de referencias implícitas a la utilización del fumus: "- antes de expropiar definitivamente vamos a ver las necesidades de tal medida, y su ajuste a la legalidad, no sea que luego, una vez llevado a cabo el Acuerdo, la resolución que se dicte sea favorable al actor y el retorno a la situación anterior sea imposible; - la empresa recurrente, en realidad, nos parece que no está encontrando más que trabas, en los últimos tiempos, en ningún caso a ella imputables, con graves perdidas y quebrantos económicos; - vemos, indiciariamente -porque tenemos que recorrer un lugar trecho hasta la sentencia y es allá donde deberemos pronunciarnos, sin que ahora podamos eludir, por otro lado, ciertas apreciaciones y matizaciones- que tal vez sea más acertado para el interés general el proyecto de la parte actora que el Gobierno de Navarra en este concreto caso; -es que, por colmo, nos encontramos con que la normativa en que se apoyan las resoluciones combatidas también se encuentra en solfa y a estos solos efectos citaremos el artículo 78. 3 de la nueva Ley del Suelo 8/1989 de 8 de julio, y aunque la incidencia de esta Ley tanto en el caso concreto como en la normativa navarra en general, deba determinarse en la sentencia, sin embargo la mínima prudencia judicial aconseja suspender el acuerdo impugnado".

Aunque las cautelas son evidentes, y sin prejuzgar como ya se ha señalado el resultado final del juicio que en un examen más pormenorizado de la cuestión puede variar por completo ("vemos, indiciariamente -porque tenemos que recorrer un largo trecho hasta la sentencia y es allá donde deberemos pronunciarnos"), no cabe duda de que implícitamente el Tribunal está admitiendo que la posición del recurrente tiene, cuando menos, un cierto fundamento.

Tenemos, pues, un ejemplo en que el fumus bonis iuris opera como criterio para el otorgamiento/denegación de una suspensión. No sólo esto, pues no sólo se tiene en cuenta, sino que resulta absolutamente decisivo, en cuanto que por el mismo cambia de signo la resolución precedente.

El empleo de este criterio está en línea con las posiciones mantenidas por nuestra mejor doctrina (GARCIA DE ENTERRIA, E. , en sus trabajos publicados sobre el caso Factortame en “REDA" 63 (1989), pág. 411 y sigs. ; 64 (1989, pág. 593 y sigs. ; y 67 (1990), pág. 401 y sigs.; y muy especialmente la reciente monografía de CHINCHILLA MARIN, M. C. , La tutela cautelar en la nueva justicia administrativa, Madrid, Civitas, 1991; tampoco pueden ser pasados por alto, aunque centrados fundamentalmente en otros 
aspectos, los trabajos sobre suspensión de RODRIGUEZ-ARANA, J. , publicados en "REDA", 64 (1989), pág. 639 y sigs. , y "PJ" (1990), pág. 179 , y su libro La suspensión en vía contenciosa, Madrid, Montecorvo, 1987).

$Y$ hoy encuentra ya plena acogida en nuestra jurisprudencia. Valga como simple botón de muestra el Auto del Tribunal Supremo de 14 de Marzo de 1990 (Ar. 3545; Pte. Trillo Torres) (que, por lo demás, recuerda la doctrina de otro Auto anterior):

“En Auto de 21 de Diciembre de 1989, dictado en la apelación 1860/89, indicábamos que en el procedimiento cautelar de suspensión de la ejecutividad de los actos administrativos residenciados ante la Jurisdicción, el presupuesto que deben examinar los Tribunales para tomar la decisión pertinente es el de que de la ejecución se puedan seguir perjuicios de reparación imposible o difícil -artículo 122 de la Ley de la Jurisdicción-, cuando el proceso es el ordinario y el de que se justifique la existencia o posibilidad de perjuicio grave para el interés general, si el proceso que se sigue es el de protección jurisdiccional de los derechos fundamentales -artículo 7. 4 de la Ley 6278 .

No obstante, señalábamos también en dicho auto que estas previsiones legales expresas no deben hacernos ignorar que en determinados casos también ha de ponderarse el valor jurídico que, en principio e inicialmente, aparenta tener la pretensión ejercitada, aun dándole a esta apreciación el alcance provisional que supone un juicio que se emite en una fase todavía tan inmadura del proceso principal, cuyo fallo desde luego no debe quedar prejuzgado $y$ teniendo en cuenta, además, que la petición de suspensión puede reproducirse, si lo considera conveniente el interesado".

En el mismo sentido -y de una forma ya definitiva- el espléndido Auto de 20 de Diciembre de 1990 (*), que comienza estableciendo como doctrina general:

(*) Este Auto -del que ha sido Ponente González Navarro- se recoge en el libro La tutela cautelar en la justicia administrativa que acaba de citarse en el texto. La autora del libro dedica a su glosa un minucioso análisis; más extenso del que aqui podemos realizar y, en consecuencia nos remitimos a él. Esta importante resolución judicial viene a demostrar una vez que si bien hard cases make bad law, es en los pequeños casos donde la Justicia con mayúsculas da los pasos cruciales. En el que nos ocupa se trataba sólo de resolver un incidente de suspensión por el cierre de un establecimiento de cuadras para el ganado ovino. 
“los estrechos límites del artículo 122 de la Ley reguladora de esta jurisdicción tienen hoy que entenderse ampliados por el expreso reconocimiento del derecho a una tutela judicial efectiva en la propia Constitución (artículo 24), derecho que implica, entre otras cosas, el derecho a una tutela cautelar. $y$ es necesario recordar también que esta fuerza expansiva del citado artículo 24 de la Constitución y su eficacia rompedora de toda irrazonable supervaloración de los privilegios administrativos como el de la presunción de validez de los actos de la Administración, viene impuesta hoy por ese principio general del derecho comunitario a que aluden las Conclusiones del Abogado general en la sentencia Factortame del Tribunal de Justicia de Luxemburgo, de 19 de Junio de 1990, principio que implícitamente hace suyo el propio Tribunal, y que se resume en que la necesidad del proceso para obtener razón no debe convertirse en un daño para el que tiene la razón.

Este principio general del derecho que, como luego se dirá, fue desvelado ya por este Tribunal Supremo hace varios años y reiterado en varias sentencias, obliga a impedir los abusos que pueden seguirse del llamado privilegio de autoejecución (...) cuando en un supuesto de hecho concreto (...) lo que se advierte prima facie, sin que ello suponga prejuzgar el fondo del pleito principal, es una apariencia -apariencia, insistimos- de buen derecho. Esta apariencia, aun siendo sólo eso, basta en un proceso cautelar para otorgar la protección provisional solicitada".

La resolución citada llega, sin embargo, más lejos todavía, en cuanto afirma que la doctrina transcrita no es ninguna novedad:

"una armónica interpretación de la dispersa regulación de las medidas cautelares en nuestro derecho positivo nacional permite descubrir, cuando se lea desde esa atalaya que es el artículo 24 de la Constitución, que aquel principio del derecho comunitario estaba ya latente, escondido, en nuestro ordenamiento, y que una jurisprudencia sensible a las líneas de evolución jurídica que marcan los nuevos tiempos -que rechazan aquella concepción sacral del poder que llevaba a ver en el individuo un súbdito y no un ciudadano- permite hacer patente".

Y así, tras recordar la dicción literal de algunos preceptos (artículo 122 de la Ley de la jurisdicción contencioso-administrativa, artículo 
116 y 72 de la Ley de Procedimiento Administrativo, artículo 56 de la Ley Orgánica del Tribunal Constitucional, y artículo 1428 de la Ley de Enjuiciamiento Civil después de su reforma de 1984), concluirá:

"Ensamblando todos estos preceptos a través de ese mecanismo articulador que es el principio de tutela judicial efectiva, fácilmente se desemboca en la consecuencia de que, contra lo que una estrecha interpretación de aquel artículo 122 de la Ley jurisdiccional parece postular, nuestro derecho nacional -al margen incluso de su inesquivable inserción en el sistema comunitario- alberga ya en su seno ese derecho a la tutela cautelar, que está inserto en aquél. Lo que, visto por su envés, significa el deber que tiene tanto la Administración como los Tribunales de acordar la medida cautelar que sea necesaria para asegurar la plena efectividad del acto terminal (resolución administrativa o, en su caso, judicial)".

Conclusión en respaldo de la cual el Auto menciona una serie de resoluciones judiciales en este sentido:

"El conjunto normativo descrito manifiesta la existencia en nuestro derecho nacional de un principio general según el cual, "la necesidad de servirse del proceso para obtener la razón no debe volverse en contra de quien tiene razón", formulado precisamente en estos términos en la sentencia de la Sala $3^{a}$ de este Tribunal Supremo de 27 de Febrero de 1990 (apelación 626/88), y que aparece ya también en otra sentencia de la misma sala de 20 de Marzo de 1990 (apelación 2580/86) con esta otra redacción: "es la Administración la que corre el riesgo de la ejecución de un acto que no es firme, de suerte que el administrado no deberá sufrir perjuicio alguno por consecuencia de una actividad de la Administración que la revisión judicial posterior declara ilegal".

En resumen, ésta es la dirección a la que el Auto objeto de este Comentario se adhiere, sin que "por supuesto $-y$ esto debe dejarse perfectamente claro- que haya una apariencia de buen derecho no supone prejuzgar el fondo, porque puede ocurrir que el estudio de fondo destruya esa apariencia en cuyo caso la sentencia que se dicte deberá desestimar las pretensiones de los que aqui aparecen como apelantes".

Ya para terminar, apuntar solamente un problema. Para aplicar el criterio del fumus existe una dificultad. Es preciso que el Tribunal 
conozca las pretensiones de las partes, y quizás existan casos en que para ello haya que esperar a la formalización de la demanda, sin que la suspensión pueda plantearse antes si el fumus es lo que va a invocarse. En fin, se trataba sólo como deciamos, de esbozar un problema; aunque a este respecto habría que resaltar dos cosas: primera, que lo señalado no significa que si el fumus puede apreciarse desde el principio haya que demorar la suspensión hasta la demanda (nuestro sistema procesal permite la adopción de la medida cautelar, incluso, antes de remitido el expediente. Buena prueba de que ello es así es el Auto del Tribunal de Justicia de las Comunidades Europeas de 28 de Junio de 1990 Comisión v. Alemania, que procede a la suspensión inmediata de una ley por ese motivo, resolución comentada entre nosotros por GARCIA DE ENTERRIA, "RIE" (1991), págs. 875 y sigs.); segunda, que de lo que no hay duda es de que, en todo caso, la fase de interposición del recurso debe abreviarse, urgiendo a la Administración a entregar el expediente y fijando plazos estrictos. Debe resolverse en cuestión de días y no de meses, como en la actualidad ocurre. La regulación dada a este aspecto del procedimiento por la Ley 62/1978, de 26 de Diciembre, bien podría servir como punto de partida, aunque también es susceptible de mejora. 